\title{
CONFERÊNCIA
}

\section{INTERVENÇÕES PEDAGÓGICAS: \\ formação pela pesquisa de Sul a Norte do Brasill}

\author{
Rafael Fonseca de Castro²
}

\section{COMENTÁRIOS INICIAIS}

O título desta fala soa diferente do habitual "De Norte a Sul", pois a metodologia sobre a qual conversaremos inicia sua trajetória no Sul do Brasil, em Pelotas, interior do Rio Grande do Sul. Depois de Teses e Dissertações defendidas nesse estado, começa a ser implementada na Região Norte, mais especificamente no estado de Rondônia.

No ano de 2020, completam dez anos desde a primeira pesquisa embasada teórico-metodologicamente na perspectiva de intervenção pedagógica: a Tese de Doutorado defendida por Pires (2010). Mas o que são as pesquisas deste tipo? O artigo publicado por Damiani et al. (2013) apresenta suas bases teórico-epistemológico-metodológicas e estabelece os critérios necessários e as fases constituintes para a sua efetivação. Segundo esses autores, são investigações que envolvem o planejamento e a implementação de interferências (mudanças, inovações pedagógicas) -

\footnotetext{
1 Conferência apresentada no I Seminário de Educação de Ariquemes, no Campus de Ariquemes/RO da Universidade Federal de Rondônia (UNIR), em 6 de novembro de 2019. Fala semelhante, com dados atualizados sobre as pesquisas em desenvolvimento pelo palestrante, foi apresentada junto ao Programa de Pós-Graduação em Educação (PPGEdu) da Universidade Federal do Pampa (Unipampa), Campus Jaguarão/RS, em 17 de dezembro de 2019.

2 Doutor em Educação. Professor do Departamento de Ciências da Educação - Campus Porto Velho. Docente Permanente do Programa de Pós-Graduação em Educação (PPGE) e do Programa de Pós-Graduação em Educação Escolar (PPGEProf). Líder do Grupo de Pesquisa "HISTCULT - Educação, Psicologia Educacional e Processos Formativos". Universidade Federal de Rondônia (UNIR). Porto Velho/RO - Brasil. E-mail: castro@unir.br. ORCID: https://orcid.org/0000-0001-5897-851X
} 
destinadas a produzir avanços, melhorias, aprimoramentos em processos educacionais - e a posterior avaliação dos efeitos dessas interferências, produzindo conhecimento científico educacional a partir de práticas pedagógicas.

Com base no que temos percebido implementando esse tipo de pesquisa, ainda é importante destacar: a sistematização, o registro e a sugestão/divulgação de boas práticas em Educação e a formação de educadores pela pesquisa.

Essa proposta metodológica se origina no Grupo de Pesquisa "Educação e Psicologia Histórico-Cultural", então liderado pela Prof. ${ }^{a}$ Dr. ${ }^{a}$ Magda Floriana Damiani, na Universidade Federal de Pelotas (UFPel), em função da necessidade de sistematizar um método às pesquisas aplicadas que vinham sendo desenvolvidos pelo grupo; por esse tipo de método, por vezes, não ser reconhecido como pesquisa, sendo tomados como projetos de ensino ou relatos de experiência ${ }^{3}$, e; o gosto pela pesquisa aplicada.

Os destaques desta conferência estão centrados nas benesses desse tipo de pesquisa, apresentados resumidamente citando as investigações realizadas com base nessa perspectiva teórico-metodológica, de Sul a Norte do Brasil, com destaque para o movimento que vem sendo desenvolvido no âmbito do Grupo de Pesquisa "HISTCULT - Educação, Psicologia Educacional e Processos Formativos" da Universidade Federal de Rondônia (UNIR).

\section{AS PESQUISAS DO TIPO INTERVENÇÃO PEDAGÓGICA}

De acordo com Damiani et al. (2013), as pesquisas do tipo intervenção pedagógica, por se tratarem de pesquisas aplicadas: voltam-se à resolução/aprimoramento de problemas/situações práticos; diferem-se da pesquisa observacional ou descritiva; visam a diminuir a distância entre a prática educacional e a produção a acadêmica e; assemelham-se a um

\footnotetext{
3 Seu reconhecimento na academia passa a ocorrer a partir da publicação do artigo que embasa a perspectiva metodológica (DAMIANI et al., 2013), das defesas de inúmeras Teses e Dissertações e da publicação de artigos científicos em periódicos.
} 
"experimento", mas dele diferem-se, essencialmente, por serem regidas, até hoje, pelo paradigma de pesquisa qualitativo.

Para Vygotsky (1927/1997), principal autor que embasa essa perspectiva: "a prática estabelece tarefas e serve de juiz supremo da teoria, como seu critério de verdade. A prática dita a forma de construir conceitos e formular leis" (p. 356). Perspectiva que vai ao encontro do que Coll, Marquesi e Palacios (1996) vislumbram em termos de Psicologia da Educação, quando afirmam que

a impossibilidade de aplicar - mecanicamente - as leis gerais do comportamento humano ao domínio da Educação obriga a empreender um tipo de pesquisa aplicada na qual os problemas, as variáveis e as características das situações educacionais devem ser particularmente levadas em conta (p. 30).

As intervenções pedagógicas compreendem, originalmente, três fases: planejamento, implementação e avaliação da intervenção (DAMIANI et al., 2013). Contudo, nas pesquisas desenvolvidas pelo Grupo HISTCULT da UNIR, inicialmente, é realizado o que temos denominado "Diagnóstico" - que institucionaliza e sistematiza o processo de aproximação dos pesquisadores com o lócus e os participantes futuros das investigações, contribuindo com a implementação e a posterior avaliação da intervenção, nos moldes empreendidos e suscitados por Luria (2010) e seus colaboradores em suas pesquisas com populações em regiões remotas.

Suas fases dividem-se entre o Método de Ensino e 0 Método de Avaliação. No primeiro, como em uma aula típica, são conhecidos os sujeitos participantes (diagnóstico), são pensadas as aulas, ações, atividades interventivas, inovações pedagógicas (planejamento) e, então, realizadas (implementação). O caráter científico desse tipo de pesquisa é constituído no Método de Avaliação, para o qual são adotados abordagens, instrumentos e análises típicos das pesquisas em Educação (BAUER e GASKELL, 2017; GIL, 2017; BARDIN, 2011; ORLANDI, 2005; MORAES, 2003). O que seria "apenas" uma inovação pedagógica, como as que ocorrem 
todos os dias nas escolas e nas universidades brasileiras, passa a ser uma pesquisa minuciosamente descrita e avaliada, com consistente filiação teórica e rígida vinculação à perspectiva metodológica ora adotada.

A coleta dos dados vem sendo realizada mediante aplicação de questionário, entrevista, análise documental, observação participante, grupo focal e/ou diário de campo (BAUER e GASKELL, 2017). A análise dos dados, por meio de análise do discurso (ORLANDI, 2005), análise de conteúdo (BARDIN, 2011) ou, principalmente, análise textual discursiva (MORAES, 2003). Das avaliações das intervenções emergem achados relacionados à realidade investigada, relativos aos efeitos da intervenção sobre seus participantes (proveniente de análise de dados em diálogo com o referencial teórico) e relativos à intervenção propriamente dita (análise crítica da intervenção, pontos fracos e fortes, dificuldades encontradas, inovações levadas a cabo, focos importantes, prospecção).

A seguir, em formato de síntese, apresentarei as pesquisas realizadas no Sul e, depois, as desenvolvidas no Norte do país, destacando as investigações promovidas na UNIR pelo Grupo de Pesquisa HISTCULT.

\section{INTERVENÇÕES PEDAGÓGICAS NO SUL: EXPERIÊNCIAS EXITOSAS NA UFPEL}

Como já mencionado, a primeira pesquisa intervenção pedagógica defendida, desenvolvida nos moldes propostos por Damiani et al. (2013), foi a de Pires (2010). Tratou-se de uma Tese de Doutorado que se propôs a planejar, implementar e avaliar duas intervenções aninhadas. A Intervenção 1, dirigida a acadêmicos do curso de Letras Espanhol, objetivou formar um grupo de futuros professores para ensino do Espanhol na Educação Especial; e a Intervenção 2, dirigida a Pessoas com Necessidades Educacionais Especiais (PNEE), na área da Deficiência Intelectual (DI), visou a promover aprendizagens e desenvolvimento no grupo participante a partir do ensino dessa língua estrangeira. Os achados de Pires (2010) contribuem com a hipótese da necessidade do investimento em atividades complexas voltadas às potencialidades das PNEE, e não aos seus déficits, e fornecem subsídios 
para as discussões sobre os currículos dos cursos de licenciatura no que concerne à importância da inclusão da temática da Educação Especial.

Em 2011, foi defendida uma Dissertação de Mestrado. Boanova (2011) visou a planejar, implementar e avaliar uma prática de ensino voltada à construção dos conhecimentos específicos sobre Retas, conteúdo da disciplina de Geometria Descritiva (GD) do curso profissionalizante em Design de Móveis do Instituto Federal Sul-rio-grandense (Campus Pelotas). A prática de ensino foi desenvolvida em Estudos Pilotos e objetivou superar as habituais dificuldades de aprendizagem nessa disciplina e desenvolver o raciocínio espacial nos estudantes. De acordo com Boanova (2011), a análise de conteúdo dos dados indicou que houve internalização adequada dos conhecimentos trabalhados por parte dos estudantes, com graus variáveis de completude e tempo necessário para aprendizagem: todos foram aprovados. A análise também sugeriu que esses resultados foram alcançados por meio das interações dialógicas e colaborativas, ocorridas entre professora e estudantes, nos momentos de exercícios, nas provas e durante as explicações usando material concreto e exemplos da vida diária. O uso da escrita também se configurou numa importante ferramenta, indicando que ela pode auxiliar no desenvolvimento do raciocínio espacial, pela tomada de consciência dos conceitos científicos que fomenta, bem como auxiliar o professor a acompanhar o processo de internalização desses conceitos, por parte dos estudantes (BOANOVA, 2011).

Em 2012, foram defendidas uma Dissertação e uma Tese. A pesquisa de Neves (2012), de Mestrado, teve como objetivo teorizar e analisar as repercussões de um conjunto de Oficinas de Jogos Teatrais do qual participou um grupo de escolares de uma quarta série do ensino fundamental de Pelotas. Mais especificamente, as repercussões foram avaliadas em termos do desenvolvimento de funções psicológicas superiores e do desenvolvimento de habilidades sociais. Os resultados verificados por Neves (2012) sugerem que os estudantes exercitaram e desenvolveram funções superiores, como atenção, concentração, tomada de consciência, 
abstração, memória sensorial e consciência corporal, assim como habilidades sociais, como o respeito ao outro, o trabalho conjunto, a desinibição frente aos colegas e adultos e a relação entre gêneros. $O$ trabalho, segundo Neves (2012), apresenta contribuição para a discussão sobre a importância do ensino de Jogos Teatrais na escola pública concernente ao desenvolvimento cognitivo e afetivo dos estudantes.

A intervenção pedagógica implementada por Rochefort (2012), em sua pesquisa de doutorado, serviu de exemplo para o artigo que definiu as bases teórico-metodológicas desse tipo de pesquisa (DAMIANI et al., 2013). Seu estudo intencionou avaliar se a intervenção favoreceu as aprendizagens dos participantes, acadêmicos de Educação Física da UFPel, relativas ao ensino do voleibol na escola e na iniciação esportiva. Tal intervenção estava assentada em dois eixos fundamentais: a) articulação entre teoria e prática e; b) trabalho em colaboração tendo, como pano de fundo, a indissociabilidade entre ensino, pesquisa e extensão. Os resultados apontaram que a intervenção pedagógica favoreceu as aprendizagens dos universitários participantes relativas ao ensino do voleibol na escola e na iniciação esportiva: a) revelaram um alto grau de internalização dos conteúdos atinentes à disciplina, expresso pelas altas médias semestrais obtidas; b) evidenciaram outras aprendizagens, relativas às habilidades e atitudes que dizem respeito ao ser professor, que se constituíram na grande contribuição da intervenção, diferenciando-a das práticas de ensino usuais, que, geralmente, parecem não atingir tal amplitude em termos de aprendizagens vinculadas ao ensinar.

Dariz (2013), por seu turno, desenvolveu pesquisa de mestrado cujo objetivo foi planejar um vídeo educativo-interativo, implementá-lo e avaliar os impactos de sua utilização para a aprendizagem de um conteúdo de Língua Portuguesa (ambiguidade lexical), em uma turma de $8^{a}$ série do Ensino Fundamental de uma escola pública de Pelotas. O vídeo foi elaborado à luz da Teoria Histórico-Cultural de Vygotsky e os achados oriundos da intervenção pedagógica sugerem que a ferramenta, por ser 
atrativa, com o uso de som, imagens e interação, foi um instrumento mediador capaz de propiciar a internalização do conteúdo, contribuindo para a tomada de consciência do conceito trabalhado, favorecendo os processos de ensino e de aprendizagem e potencializando maior desenvolvimento mental entre os partícipes (DARIZ, 2013).

Também em 2013, Alves (2013), em sua Tese de Doutoramento, avaliou os efeitos de uma intervenção pedagógica sobre o desenvolvimento da tomada de consciência e da capacidade de controle da escrita e sobre o emprego de funções psicológicas superiores relacionadas a essa atividade, em um grupo de estudantes do Curso de Licenciatura em Pedagogia da UFPel. O estudo foi amparado pelos preceitos da abordagem psicológica Histórico-Cultural e da Linguística Textual e a intervenção empreendida com base em processos interpsicológicos e na abordagem processual de texto. Os resultados do estudo de Alves (2013) indicam que o ensino da produção de textos escritos, mediado pelos processos interpsicológicos e pela abordagem processual de texto, possibilita aos estudantes tornarem-se escritores mais proficientes.

Castro (2014) também desenvolveu uma intervenção pedagógica voltada à escrita de professores em formação em seu doutorado, mas com estudantes de um Curso de Pedagogia a distância. As etapas da intervenção intencionavam contribuir para o aprimoramento da expressão escrita de um grupo de acadêmicas e foram guiadas, fundamentalmente, pelos conceitos vygotskianos de consciência e controle. A implementação foi efetivada por meio de constante diálogo com as acadêmicas, intervindo diretamente em seus textos e enfatizando a importância de desenvolverem consciência sobre os próprios problemas de escrita para que, então, pudessem corrigi-los, controlá-los. Os resultados de Castro (2014) permitem afirmar que as intervenções colaboraram para a melhora da escrita das acadêmicas em termos de organização macroestrutural dos textos, uso de conectivos e pontuação, contribuindo para o desenvolvimento de estratégias relacionadas ao ensino e à aprendizagem da escrita e 
configurando-se em uma boa prática relacionada ao ensino da escrita entre universitários - realizada 100\% via Ambiente Virtual de Aprendizagem (AVA).

Também em 2014, Pinheiro (2014) defendeu pesquisa de doutorado que teve como objetivo, tomando como base as ideias de Lev Vygotsky, Alexis Leontiev e Daniil Elkonin, investigar se o jogo com regras explícitas, no contexto de intervenções individualizadas, pode: 1) ser um instrumento para o sucesso em estudantes do $3^{\circ}$ e $4^{\circ}$ ano do ensino fundamental que apresentam história de fracasso escolar; e 2) influenciar o desenvolvimento de funções psicológicas superiores, como a percepção, a atenção, a memória, o raciocínio e a tomada de consciência. Os resultados verificados por Pinheiro (2014) sugerem que as aprendizagens, ocorridas nas intervenções com a mediação dos jogos e da pesquisadora, promoveu o desenvolvimento dessas funções e isso se refletiu no desempenho escolar dos estudantes: eles foram aprovados para a série seguinte e percebeu-se também efeitos no autoconceito relativo ao desempenho escolar e na autoestima dos sujeitos, que suscitaram mudanças no seu relacionamento interpessoal e no cuidado de si.

A última intervenção defendida no âmbito do Grupo de Pesquisa da UFPel, e orientada pela Prof. a Magda Damiani, foi a Tese de Doutorado de Cenci (2015), que se voltou à inclusão de alunos com deficiência no $6^{\circ}$ ano do ensino fundamental na cidade de Pelotas, focada em suas aprendizagens e não apenas na sua presença na escola. Visou, igualmente, a investigar a compreensão que os professores tinham acerca da inclusão e buscar um entendimento ampliado acerca do tema que pudesse orientar a produção, pelo próprio grupo, de novas formas de organização do ensino para promover essas aprendizagens (aprendizagem expansiva). Ao fim da pesquisa, Cenci (2015) percebeu que as contradições geradas pela inclusão dos alunos com deficiência na escola regular são grandes demais para serem enfrentadas com as condições disponíveis aos professores. Além disso, avaliou que a intervenção não deu suporte suficiente para tais transformações, já que apenas poucas mudanças individuais foram 
observadas, não podendo serem consideradas como transformações do objeto da atividade e nem como aprendizagens expansivas.

\section{INTERVENÇÕES PEDAGÓGICAS NO NORTE: EXPERIÊNCIAS EXITOSAS NA UNIR}

Desde 2017, com a minha chegada na UNIR, e a consequente institucionalização do Grupo de Pesquisa HISTCULT nesse mesmo ano, trabalhei para desenvolver pesquisas do tipo de intervenção pedagógica também na graduação e pelo Programa Institucional de Bolsas de Iniciação Científica (PIBIC), bem como nos programas de pós-graduação aos quais me vinculei, o Mestrado Profissional em Saúde da Família (PROFSAÚDE) e o Mestrado Acadêmico em Educação do Programa de Pós-Graduação em Educação (MEDUC-PPGE).

Em 2017, foi aprovado o Plano de Trabalho de pesquisa PIBIC intitulado "Intervenção Pedagógica: ações educacionais e produção de conhecimento em escolas da Zona Rural de Porto Velho/RO", que contou com a participação de uma bolsista e uma voluntária, ambas acadêmicas do Curso de Pedagogia da UNIR, culminando com o Trabalho de Conclusão de Curso (TCC) defendido, em 2018, por Araújo (2018). O TCC retrata intervenções realizadas em duas escolas de Zona Rural de Porto Velho. Na Escola 1, foi reorganizado e reformatado, pedagogicamente, o espaço da biblioteca, antes não utilizada pela instituição. Todos os professores reconheceram a importância desse espaço, porém, não o utilizam simplesmente pelo fato de não estar disponível, o que mudou após a intervenção. Na Escola 2, após apenas seis etapas interventivas, quatro alunos selecionados pela Direção conseguiram mostrar avanços em leitura e escrita, operando com hipóteses mais concretas, menos confusão com algumas letras e correção de erros ortográficos. As atividades propostas e o material utilizado deram respostas positivas no comparativo pré e pósintervenção. Foi, ao mesmo tempo, a primeira intervenção pedagógica empreendida na graduação e na iniciação científica. 
A publicação de Castro et al. (2018) também se baseou em uma ação desenvolvida na graduação, desta vez, com estudantes do curso de Licenciatura em Ciências Biológicas da UNIR. A pesquisa teve origem em um movimento interdisciplinar entre as disciplinas de Didática e Estágio Supervisionado que culminou em onze intervenções pedagógicas em escolas públicas de Porto Velho. Cinco delas capturaram as impressões dos sujeitos (os alunos dos estagiários) e indicaram: 1. recepção positiva dos estudantes às aulas práticas e às diferentes didáticas propostas pelos acadêmicos-estagiários e 2. motivação em participarem das feiras de ciências e das atividades de conscientização ambiental. Os resultados corroboraram a defesa dos autores sobre a importância da diversidade didática nas aulas de Biologia para despertar maior interesse dos estudantes e promover aprendizagens mais significativas.

Outros dois movimentos relacionados às intervenções pedagógicas na graduação cabem ser mencionados: na disciplina Estágio Supervisionado em Gestão Escolar do curso de Licenciatura em Pedagogia e na disciplina de Psicologia do curso de Licenciatura em História. Em ambas, é solicitado apenas o Projeto de Intervenção e os acadêmicos são levados a pensar sobre determinado contexto educacional concreto e a planejar ações inovadoras para aprimorar situações nesses contextos ou a superar problemas verificados na etapa de Diagnóstico. O caso dos estágios em Gestão Escolar foi além, substituindo o tradicional Relatório de Estágio pelo Projeto de Intervenção: este último de apresentação obrigatória pelos estagiários nas escolas, constituindo devolutiva importante da universidade.

Outro TCC desenvolvido mediante diagnóstico, planejamento, implementação e avalição de uma intervenção foi defendido por Santos (2019). Tratou-se de outra aplicação inédita em termos desse tipo de pesquisa: adotou como lócus uma experiência de educação não-formal. Essa pesquisa teve por objetivo realizar intervenções pedagógicas no Programa Forças no Esporte (PROFESP) de Porto Velho, mediando o ensino de conceitos científicos de matemática a três crianças que cursavam o 
quarto ano do ensino fundamental regular. Os resultados da avaliação da intervenção permitem afirmar que as atividades didáticas colaboraram para a compreensão da lógica das operações básicas da matemática pelos participantes e a importância dos conceitos científicos e do pensamento abstrato para o desenvolvimento cognitivo das crianças (SANTOS, 2019).

Em 2019, outra pesquisa inédita, realizada por Penha (2019). Utilizou-se da metodologia com o objetivo de implantar uma rotina protocolar em uma Unidade Básica de Saúde (UBS) de Porto Velho, sendo a primeira intervenção pedagógica implementada na área da saúde. O trabalho de Penha (2019) implantou parcialmente a rotina de Atenção à Saúde da Pessoa Idosa em uma equipe de saúde da família na UBS Pedacinho de Chão. A implantação da rotina se baseou no planejamento, na implementação e na avalição de ações de formação em serviço, na UBS e em visitas domiciliares, junto aos membros da equipe.

No MEDUC, outras quatro pesquisas de mestrado estavam sendo desenvolvidas baseadas no supracitado tipo de pesquisa ${ }^{4}$. Em 2019, Stangue (2019) defendeu intervenção pedagógica similar às de Alves (2013) e Castro (2014), mas sobre a escrita de acadêmicos de Pedagogia do Campus de Ariquemes da UNIR. Sua intervenção caracterizou-se pela realização de práticas pedagógicas inovadoras relativas ao ensino da escrita, avaliadas ao final, e os principais resultados indicaram entre os sujeitos: 1. ampliação da tomada de consciência acerca de seus problemas de escrita; 2. percepção acerca da necessidade de revisar os textos e de transmitir informações coesas e precisas aos interlocutores; 3. entendimento sobre a importância de conhecer os conteúdos científicos de língua portuguesa e de sua aplicabilidade na escrita; 4. aumento das possibilidades de controle relacionado à produção de textos, em especial, ao uso da vírgula, do pontofinal e de conectivos e; 5 . avaliação positiva da intervenção, reforçando a importância de ações pedagógicas sistematizadas para o ensino da escrita, associando as normas da língua padrão à produção textual. (2020) e Pinho (2020), ambas intervenções pedagógicas defendidas em 2020. 
https://doi.org/10.24065/2237-9460.2021v11n1ID1514

No cômputo geral, na UNIR5, foram: no curso de Pedagogia, dois TCC e 37 Projetos de Intervenção na disciplina de Estágio Supervisionado em Gestão Escolar, entre 2017 e 2018; no curso de Ciências Biológicas, onze Projetos de Intervenção, sendo cinco avaliados ao final e um artigo publicado sistematizando essas intervenções, em 2017; no curso de História, 33 Projetos de Intervenção elaborados pelas turmas de Psicologia da Educação, entre as turmas de 2018 e 2019; no PROFSAÚDE, uma dissertação defendida em 20196; no MEDUC, quatro dissertações, sendo uma defendida em 2019, duas em 2020 e uma em andamento7. Ainda, é imperativo mencionar o Projeto de Pesquisa que abarca as pesquisas citadas e outras, denominado "Intervenções Pedagógicas em Rondônia: inovação educacional e produção de conhecimento em Educação", institucionalizado por mim na UNIR, pelo Grupo de Pesquisa HISCULT8.

\section{CONSIDERAÇÕES FINAIS}

As pesquisas do tipo intervenção pedagógica têm apresentado representativa versatilidade, sendo empreendidas em diversas áreas do conhecimento (Pedagogia, Educação Especial, Educação Física, Matemática, Letras, História, Biologia, Saúde da Família e Artes) e em diferentes graus da Educação Formal (Educação Infantil, Anos Iniciais e Anos Finais do Ensino Fundamental, Ensino Superior e Pós-Graduação), sendo empregada até na Educação não-formal.

Outros pontos merecem destaque, tais quais: resultados imediatos em termos de formação inicial e continuada de educadores-pesquisadores; forte ênfase na relação pesquisa-ensino; estudos aprofundados relacionados

\footnotetext{
5 Números atualizados pelo autor em 12 de janeiro de 2020 para a publicação desta conferência.

6 Atualizado pelo autor após a conferência: outra pesquisa intervenção pedagógica pelo PROFSAÚDE, que seria defendida em 2020, em decorrência da pandemia global de COVID19, precisou ser readaptada para pesquisa exploratória (GIL, 2017).

7 Atualizado pelo autor após a conferência: outra pesquisa intervenção pedagógica pelo MEDUC, que seria defendida em 2020, em decorrência da pandemia global de COVID-19, precisou ser readaptada para pesquisa exploratória (GIL, 2017).

8 Portaria n. ${ }^{\circ} 81 / 2019 /$ PROPESQ/UNIR.
} 
à metodologia de pesquisa em Educação; aproximações teóricas inovadoras; estreitamento da relação Universidade-Escola; devolutiva às comunidades escolares e, consequentemente, à sociedade.

Alguns cursos trabalham com a premissa de que os produtos finais de seus discentes sejam concebidos a partir de pesquisas aplicadas, como nos casos da Especialização em Mídias na Educação do IF-Sul e do Mestrado Profissional em Educação da Unipampa (Campus Jaguarão), adotando/sugerindo a perspectiva de intervenção pedagógica como referência teórico-metodológica. Assim como as pesquisas de mestrado e de doutorado do Programa de Pós-Graduação em Educação Escolar (PPGEProf) da UNIR.

Também cabe sublinhar a proposta do Curso de Especialização em Saúde da Família (EaD), ofertado de 2011 a 2016 pelo Departamento de Medicina Social (DMS) da UFPel, no qual os TCC de todos os discentes deveriam se basear em intervenções realizadas nas UBS onde atuavam, devendo todas as intervenções partirem de um diagnóstico situacional da realidade do serviço, serem planejadas com base em um protocolo relacionado a uma atenção programática típica de Atenção Primária à Saúde (APS) e avaliadas a partir de objetivos, metas e ações. Ao total, foram defendidas mais de 2000 intervenções que mudaram, efetivamente, a realidade do atendimento a muitas pessoas, em todos os estados do Brasil.

As pesquisas intervenção pedagógica seguem sendo implementadas na Região Norte do Brasil, essencialmente, no estado de Rondônia, pelo Grupo de Pesquisa HISTCULT da UNIR, mas é importante a disseminação dessa proposta metodológica, que seja adotada por outros grupos, em outras instituições. Foram pesquisas, até então, fortemente baseadas na Teoria Histórico-Cultural da Atividade, contudo, é recomendável que outros referenciais teóricos possam embasar esse tipo de pesquisa para que discussões epistemológicas possam ser empreendidas no campo da metodologia da pesquisa em Educação. 


\section{REFERÊNCIAS}

ALVES, Clarice. Vaz Peres. A escrita no contexto acadêmico: uma abordagem a partir das Ideias de L. S. Vygotsky. 2013. 232f. Tese (Doutorado em Educação) - Universidade Federal de Pelotas, Pelotas, 2013.

ARAÚJO, Gabrielle F. S. Intervenção Pedagógica e Educação do Campo: ações educacionais em duas escolas de Zona Rural de Porto Velho/RO. 2018. 59f. Trabalho de Conclusão de Curso (Licenciatura em Pedagogia) Universidade Federal de Rondônia, Porto Velho, 2018.

BARDIN, L. Análise de conteúdo. São Paulo: Edições 70, 2011.

BAUER, Martin. W.; GASKELL, George. (Orgs.). Pesquisa Qualitativa com Texto, Imagem e Som: um manual prático. 6. ed. Petrópolis: Vozes, 2017.

BOANOVA, Cecília O. Análise de uma proposta de ensino de geometria descritiva baseada na perspectiva histórico-cultural. 2011. 112 f. Dissertação (Mestrado em Educação) - Universidade Federal de Pelotas, Pelotas, 2011.

CASTRO, Rafael F. de. A expressão escrita de acadêmicas de um curso de pedagogia a distância: uma intervenção Histórico-Cultural. 2014. 238f. Tese (Doutorado em Educação) - Universidade Federal de Pelotas, Pelotas, 2014.

CASTRO, Rafael F. de; CARVALHO, Anjo G.; BRITO, Hevelyn Plácido; BERBET, Geísa; CUNHA, Kellen K. C. Propostas de intervenção pedagógica de estagiários para o ensino de Biologia em escolas públicas de Porto Velho. EDUCA - Revista Multidisciplinar em Educação, Porto Velho, v. 05, n. 12, p. 61 81, set/dez, 2018. Disponível em: https://www.periodicos.unir.br/index.php/EDUCA/article/view/3226. Acesso em: 03 mar. 2019.

CENCl, Adriane. "Inclusão é uma utopia": possibilidades e limites para a inclusão nos anos finais do ensino fundamental - intervenção e interpretação a partir da Teoria Histórico-Cultural da Atividade. 2016. 335f. Tese (Doutorado em Educação) - Universidade Federal de Pelotas, Pelotas, 2016.

COLL, C.; MARQUESI, A.; PALACIOS, J. (Orgs.). Desenvolvimento psicológico e educação: Psicologia da educação. Vols. I, II e III. Porto Alegre: Artes Médicas, 1996.

DAMIANI, Magda F. ROCHEFORT, Renato S. CASTRO, Rafael F. de; PINHEIRO, Silvia N. S.; DARIZ, Marion R. Discutindo pesquisas do tipo intervenção pedagógica. Cadernos de Educação, Pelotas, v. 45, n. 1, 2013. Disponível em: https://periodicos.ufpel.edu.br/ojs2/index.php/caduc/article/view/3822. Acesso em: 28 jun. 2019. 
GIL, Antônio C. Como elaborar projetos de pesquisa. 6. ed. São Paulo: Atlas, 2017.

LURIA, A. R. Desenvolvimento Cognitivo. 6. ed. São Paulo: Ícone, 2010.

MORAES, Roque. Uma tempestade de luz: a compreensão possibilitada pela análise textual discursiva. Ciência e educação, Bauru, v. 9, n. 2, p. 191-211, 2003. Disponível em: http://dx.doi.org/10.1590/S1516-73132003000200004. Acesso em: 19 ago. 2019.

NEVES, Ângela B. Oficinas de Jogos Teatrais e suas repercussões em Escolares. 2012. 112 f. Dissertação (Mestrado em Educação) - Universidade Federal de Pelotas, Pelotas, 2012.

ORLANDI, Eni P. Análise de Discurso. Princípios e Procedimentos. 5. ed. Campinas: Pontes, 2005.

PENHA, Soraia R. A implantação de uma rotina de atenção à saúde da pessoa idosa em uma equipe de Saúde da Família de Porto Velho/RO. 2019. 103f. Dissertação (Mestrado Profissional em Saúde da Família) - Universidade Federal de Rondônia, Porto Velho, 2019.

PINHEIRO, Silvia N. S. O jogo com regras explícitas pode ser um instrumento para o sucesso de estudantes com história de fracasso escolar? 2014. $218 \mathrm{f}$. Tese (Doutorado em Educação) - Universidade Federal de Pelotas, Pelotas, 2014.

PINHO, Franciane de Oliveira. Mediação de Conflitos: proposta de intervenção pedagógica por uma nova cultura de convivência em uma escola estadual do município de Porto Velho/RO. 2020. 199f. Dissertação (Mestrado em Educação) - Universidade Federal de Rondônia, Porto Velho, 2020.

PIRES, Fabiana L. B. O ensino da Língua Espanhola na Educação Especial: formação docente e aprendizagem de pessoas com Deficiência Intelectual. 2010. 278f. Tese (Doutorado em Educação) - Universidade Federal de Pelotas, Pelotas, 2010.

ROCHEFORT, Renato S. Ensinar a ensinar... Aprender para ensinar! As aprendizagens na formação inicial em Educação Física nas perspectivas das Teorias Histórico-Cultural e da Atividade. 2012. 347f. Tese (Doutorado em Educação) - Universidade Federal de Pelotas, Pelotas, 2012.

SANTOS, Divina Rogéria C. Intervenção Pedagógica na Educação NãoFormal: uma proposta junto a crianças do PROFESP na cidade de Porto Velho/RO. 2019. 99f. Trabalho de Conclusão de Curso (Licenciatura em Pedagogia) - Universidade Federal de Rondônia, Porto Velho, 2019. 
SILVA, Ana Cláudia O. "Jogo de Figuras e Palavras": uma proposta de intervenção pedagógica para os anos iniciais do ensino fundamental. 2020. 178f. Dissertação (Mestrado em Educação) - Universidade Federal de Rondônia, Porto Velho, 2020.

STANGUE, Rosemeri K. A Escrita na Perspectiva Histórico-Cultural: uma Intervenção com Acadêmicos de Pedagogia de Ariquemes (RO). 2019. $150 f$. Dissertação (Mestrado em Educação) - Universidade Federal de Rondônia, Porto Velho, 2019.

VYGOTSKI, Lev S. Obras Escogidas. v. 1. 2. ed. Moscú: Editorial Pedagóguika, $1927 / 1997$.

Recebida em: 10 de setembro de 2020

Aprovada em: 06 de novembro de 2020

Publicada em: 18 de janeiro de 2021 